\title{
Detection and Estimation of alpha-Amyrin, beta-Sitosterol, Lupeol, and $n$-Triacontane in Two Medicinal Plants by High Performance Thin Layer Chromatography
}

\author{
Saikat S. Mallick and Vidya V. Dighe \\ Chemistry Department, Ramnarain Ruia College, Matunga East, Mumbai, Maharashtra 400 019, India \\ Correspondence should be addressed to Saikat S. Mallick; mallisaikat@gmail.com
}

Received 18 May 2014; Revised 5 August 2014; Accepted 5 September 2014; Published 22 September 2014

Academic Editor: Liya Ge

Copyright ( 2014 S. S. Mallick and V. V. Dighe. This is an open access article distributed under the Creative Commons Attribution License, which permits unrestricted use, distribution, and reproduction in any medium, provided the original work is properly cited.

\begin{abstract}
A normal phase high performance thin layer chromatography (HPTLC) method has been developed and validated for simultaneous estimation of four components, namely, alpha-amyrin, beta-sitosterol, lupeol, and n-triacontane from two medicinally important plants, Leptadenia reticulata Wight \& Arn. and Pluchea lanceolata (DC.) CB. Clarke. In Ayurveda, both plants have been reported to possess immunomodulatory activity. Chromatographic separation of the four components from the methanolic extracts of whole plant powders of Leptadenia reticulata Wight \& Arn. and Pluchea lanceolata (DC.) CB. Clarke. was performed on TLC aluminium plates precoated with silica gel $60 \mathrm{~F}_{254}$ using a suitable mobile phase. The densitometric scanning was done after derivatization at $\lambda=$ $580 \mathrm{~nm}$ for $\alpha$-amyrin, $\beta$-sitosterol, and lupeol, and at $366 \mathrm{~nm}$ for $n$-triacontane. The developed HPTLC method has been validated and used for simultaneous quantitation of the four components from the methanolic extracts of whole plant powders of Leptadenia reticulata Wight \& Arn. and Pluchea lanceolata (DC.) CB. Clarke. The developed HPTLC method is simple, rapid, and precise and can be used for routine quality control.
\end{abstract}

\section{Introduction}

Herbal medicines have been used since ages to treat various ailments. Ayurveda is an Indian traditional system of medicine used since ancient times. It has a huge list of herbs used in various forms for treatment of different disease conditions. Owing to the medicinal properties attributed to herbal drugs, it is necessary to maintain their quality and purity, thereby justifying their acceptability in modern system of medicine. Standardisation of these herbal drugs is a challenge to the entire scientific fraternity. However, due to lack of suitable quality control and quality assurance standards for herbal drugs, it becomes difficult to ensure uniformity of their composition which in turn affects the efficacy of their final products. Analytical tools are important for qualitative, semiquantitative, and quantitative phytochemical analysis of herbal drugs and formulations. Chromatographic techniques such as high performance liquid chromatography (HPLC), high performance thin layer chromatography (HPTLC), and gas chromatography (GC) are used to efficiently determine the quality of the herbs by developing fingerprints and estimation of biomarkers. Among the wide choice of chromatographic techniques, HPTLC is a simple, fast, and accurate technique for use, making it advantageous over others for quick assessment of a number of samples simultaneously [1]. In the present research work, HPTLC method has been developed as a quality control tool for whole plant powder of $L$. reticulata and P. lanceolata.

L. reticulata belonging to family Asclepiadaceae commonly known as "Jivanti" has been reported to possess antitumour and anticancer activity [2]. P. lanceolata belonging to family Asteraceae commonly known as "Rasna" is an important xerophytic medicinal herb. It is traditionally used for dyspepsia, bronchitis, and rheumatoid arthritis [3, 4]. In Ayurveda both plants have been reported to be used as a "Rasayana" for immunomodulatory activity [5]. Previous chemical studies of $L$. reticulata showed the presence of flavonoids, triterpenes, and steroids. It is also a rich source 
of biologically active cardiac and pregnane glycosides [2]. $P$. lanceolata contains high amounts of medicinally important secondary metabolites, namely, quercetin, beta-sitosterol, triterpenoids, and so forth [6, 7].

Among all phytochemicals, beta-sitosterol is a main phytosterol found in many plants. It has been reported to show anti-inflammatory, antineoplastic, antipyretic, and immunomodulating activity [8]. Also triterpenoids are among commonly present secondary metabolites in plants. alpha-Amyrin, a pentacyclic triterpenoid, has been reported to show anti-inflammatory properties. Lupeol has been reported to show anticarcinogenic and antitumour activity [9].

$n$-Triacontane has been reported to be present in number of plants including $L$. reticulata. $n$-Triacontane has also been reported to be tested for biological activity such as antibacterial, antidiabetic, and antitumor activity [10-12].

Some of the analytical methods for qualitative analysis of alpha-amyrin, beta-sitosterol, lupeol, and $n$-triacontane from other plant samples are discussed herewith. RP-HPTLC separation of twelve compounds including alpha-amyrin, lupeol, and beta-sitosterol from Brassica oleracea L., Solanum lycopersicum L., Rosmarinus officinalis L., Salvia officinalis L., and Quercus robur L. was carried out [9]. Another normal phase HPTLC technique was also reported for separation and determination of alpha-amyrin and lupeol from Brassica oleracea L. leaf extracts. Visual estimation after derivatization using anisaldehyde-sulphuric acid was carried out [13]. A method comprising capillary GC was used to accurately quantitate alpha-amyrin, beta-sitosterol, and lupeol from aerial part of J. anselliana as reported [14]. A gas chromatography-mass spectrometry (GC-MS) method was used for analysing compounds in Salvia bicolour Desf. extract. Among various compounds, lupeol and betasitosterol were determined [15]. A method was reported to study the chemical constituents of the essential oil of Laggera pterodonta (DC.) Sch. Bip. using GC-MS [16]. Percentage of $n$-triacontane in essential oil of Laggera pterodonta (DC.) Sch. Bip. was evaluated.

However, no method was applied for quantifying the presence of alpha-amyrin, beta-sitosterol, lupeol, and $n$ triacontane simultaneously from $L$. reticulata and $P$. lanceolata.

Hence, in present research work, a simple, rapid, precise, and accurate HPTLC method has been developed and validated using International Conference on Harmonization $(\mathrm{ICH})$ guidelines for simultaneous determination and quantification of alpha-amyrin, beta-sitosterol, lupeol, and $n$ triacontane form dried whole plant powder of L. reticulata. and P. lanceolata.

\section{Experimental Methods}

2.1. Experimental Reagents. The solvents, acetonitrile (purity 99.9\%), petroleum ether (purity 99.8\%), ethyl acetate (purity 99.0\%), methanol (purity 98.9\%), and chloroform (purity 99.9\%) were obtained from E. Merck (India). The precoated TLC $60 \mathrm{~F}_{254}$ plates were obtained from E. Merck (India).
2.2. Reference Standards. Reference standards alpha-amyrin (purity 99.3\%), beta-sitosterol (purity 99.8\%), lupeol (purity 99.7\%), and $n$-triacontane (purity 98.9\%) were procured from Sigma-Aldrich Chemie GmbH (Aldrich Division, Steinbeim, Germany).

2.3. Plant Materials. Whole plant of L. reticulata was collected from Bhumel village, district of Nadiad, Gujarat. The plant material was authenticated from Agarkar Research Institute, Pune, India (Voucher no. WP-090). Whole plant of $P$. lanceolata was collected from Sonamukhi Nagar, Jodhpur, India. Herbarium of $P$. lanceolata was authenticated from Botanical Survey of India, Pune, India (Certificate no. BSI/WRC/Tech./2012/79).

The duplicate herbaria of both the plants were prepared and are preserved in Ramnarain Ruia College, Matunga, India, for future reference. Both plant materials were washed with water to remove soil particles, dried in shade, finely powdered and then sieved through BSS mesh size 85, and stored in an airtight container at room temperature $(25 \pm$ $\left.2^{\circ} \mathrm{C}\right)$.

\subsection{Preparation of Solutions}

2.4.1. Preparation of Stock Solution of alpha-Amyrin, betaSitosterol, Lupeol, and n-Triacontane. About $10.0 \mathrm{mg}$ of alpha-amyrin was accurately weighed and transferred to $10.0 \mathrm{~mL}$ volumetric flask. $5.0 \mathrm{~mL}$ of methanol solution was added into the volumetric flask and sonicated in an ultrasonic bath (Model: TRANS-O-SONIC, Frequency: $50 \mathrm{~Hz}$ ) for 5 minutes for complete dissolution of alpha-amyrin. The volume was then made up to the mark with methanol. A stock solution of alpha-amyrin with concentration of $1000 \mu \mathrm{g} / \mathrm{mL}$ was prepared. Similarly stock solutions of beta-sitosterol and lupeol were prepared. Stock solution of $n$-triacontane was prepared by taking accurately weighed $100 \mathrm{mg} n$-triacontane in a $10.0 \mathrm{~mL}$ volumetric flask and initially dissolving it in $5.0 \mathrm{~mL}$ chloroform as described above. The volume in the standard flask was then made up to the mark with methanol. A stock solution of $n$-triacontane with concentration of $10,000 \mu \mathrm{g} / \mathrm{mL}$ was prepared.

2.4.2. Preparation of Working Standard Solution of alphaAmyrin $(50.0 \mu \mathrm{g} / \mathrm{mL})$, beta-Sitosterol $(50.0 \mu \mathrm{g} / \mathrm{mL})$, Lupeol $(50.0 \mu \mathrm{g} / \mathrm{mL})$, and $n$-Triacontane $(500.0 \mu \mathrm{g} / \mathrm{mL}) .0 .50 \mathrm{~mL}$ of above stock solution of each standard was then transferred to $10.0 \mathrm{~mL}$ volumetric flask and the contents of volumetric flask were diluted up to $10.0 \mathrm{~mL}$ by methanol to obtain mixture four standards of alpha-amyrin, beta-sitosterol, lupeol with concentration $50.0 \mu \mathrm{g} / \mathrm{mL}$ each, and standard of $n$ triacontane with concentration $500.0 \mu \mathrm{g} / \mathrm{mL}$.

2.4.3. Preparation of Sample Solution. About $1.0 \mathrm{~g}$ of dried powder of whole plant of $L$. reticulata was accurately weighed and transferred to a $100 \mathrm{~mL}$ stoppered conical flask. $25.0 \mathrm{~mL}$ of methanol: chloroform $(1: 1, \mathrm{v} / \mathrm{v})$ was added to it and the flask was sonicated in an ultrasonic bath for 15 minutes. The flask was then shaken at $50 \mathrm{rpm}$, on a conical flask 
shaker overnight at room temperature $\left(25 \pm 2^{\circ} \mathrm{C}\right)$. Sample was filtered through Whatman filter paper no. 1 . The filtrate was then finally filtered using $0.45 \mu \mathrm{m}$ nylon filters (Millipore), collected in a beaker, and then evaporated on a hot water bath. The final volume was then made up to $10 \mathrm{~mL}$ with methanol : chloroform $(1: 1, \mathrm{v} / \mathrm{v})$ in a $10 \mathrm{~mL}$ volumetric flask. The same procedure was followed for preparation of extract of whole plant of $P$. lanceolata.

2.4.4. Prederivatization Reagent. The standards and sample solution were applied in the form of a band on TLC plate. This plate was subjected to prederivatization by iodine. Iodine vapours were generated by heating iodine crystals in a closed stoppered flat bottom conical flask. The plate was then exposed to the iodine vapour in a dark enclosed chamber, for 10 minutes. After that, the plate was removed from the chamber and heated on Camag TLC plate heater at $100^{\circ} \mathrm{C}$ for 10 minutes, till the excessive iodine was removed. This prederivatized plate was finally used for development.

2.4.5. Preparation of Mobile Phase. The mobile phase used in the present research work for simultaneous quantification of alpha-amyrin, beta-sitosterol, and lupeol was prepared by mixing petroleum ether, ethyl acetate, and acetonitrile in the volume ratio of $8.2: 1.8: 0.1$. During development of each plate, a fresh mobile phase was prepared.

2.4.6. Postderivatization Reagent. Anisaldehyde-sulphuric acid reagent was used as postderivatizing reagent. Anisaldehyde-sulphuric acid reagent was prepared by taking $10 \mathrm{~mL}$ of sulphuric acid, which was added to an ice cooled mixture of methanol $(170.0 \mathrm{~mL})$ and glacial acetic acid $(20.0 \mathrm{~mL})$. Further, $1.0 \mathrm{~mL}$ of anisaldehyde solution was added to the above mixture of methanol, glacial acetic acid, and sulphuric acid. The solvent mixture was thoroughly mixed by shaking and used as per requirement.

2.4.7. Chromatography. The Chromatography was performed on $20 \mathrm{~cm} \times 10 \mathrm{~cm}$ TLC aluminum precoated silica gel $60 \mathrm{~F}_{254}$ plate, with $200 \mu \mathrm{m}$ layer thickness (E. Merck, Mumbai, India). Standard and sample solutions were applied to the plates as $8 \mathrm{~mm}$ bands, $6 \mathrm{~mm}$ apart from each other and $10 \mathrm{~mm}$ from bottom edge of the plate, under a continuous supply of nitrogen by means of a Camag Linomat V TLC sample applicator with a $100 \mu \mathrm{L}$ syringe (Hamilton, Bonaduz, Switzerland). After the application, prederivatization was performed by exposing the plate to iodine vapour for 10 minutes. The prederivatized plate was developed vertically ascending in a twin-trough glass chamber (Camag, Switzerland) saturated with mobile phase comprising petroleum ether : ethyl acetate : acetonitrile $(8.2: 1.2: 0.1 \mathrm{v} / \mathrm{v} / \mathrm{v})$. The optimized chamber saturation time for the mobile phase was 20 minutes at room temperature $\left(25 \pm 2^{\circ} \mathrm{C}\right)$. The chromatographic run length was $90 \mathrm{~mm}$ from the bottom edge of the plate. After development, the plate was air dried for complete removal of mobile phase and derivatized by dipping the developed plate in anisaldehyde-sulphuric acid reagent for 2 seconds. The plate was then air-dried for complete removal of anisaldehyde-sulphuric acid and heated at $110^{\circ} \mathrm{C}$ for 10 minutes. Densitometric scanning was then performed at $\lambda=580 \mathrm{~nm}$ for alpha-amyrin, beta-sitosterol, and lupeol in reflectance/absorbance mode and $\lambda=366 \mathrm{~nm}$ for $n$ triacontane using Camag TLC scanner 4 with winCATS software version 1.4.6. The slit dimension used was $6.0 \times 0.45 \mathrm{~mm}$ (micro) with scanning speed of $20 \mathrm{~mm} / \mathrm{sec}$, throughout the analysis.

\subsection{Method Validation}

2.5.1. Linear Working Range of alpha-Amyrin, beta-Sitosterol, Lupeol, and n-Triacontane. Determination of linear dynamic range concentration of alpha-amyrin, beta-sitosterol, lupeol, and $n$-triacontane was done by applying $2 \mu \mathrm{L}, 4 \mu \mathrm{L}, 6 \mu \mathrm{L}, 8 \mu \mathrm{L}$, $10 \mu \mathrm{L}, 12 \mu \mathrm{L}, 14 \mu \mathrm{L}, 16 \mu \mathrm{L}, 18 \mu \mathrm{L}, 20 \mu \mathrm{L}$, and $22 \mu \mathrm{L}$ on TLC plate of working standard containing alpha-amyrin, betasitosterol, lupeol, and $n$-triacontane.

The peak areas obtained from densitograms for each applied concentration of alpha-amyrin, beta-sitosterol, lupeol, and $n$-triacontane were noted.

The calibration curves of all four standards were obtained by plotting graphs of mean peak areas of each standard versus corresponding concentration (Figure 1). The results, listed in Table 1, show that within the concentration range indicated, there was a good correlation between mean peak area and concentration of standards.

2.5.2. Limit of Detection (LOD) and Limit of Quantification (LOQ). The limit of detection (LOD) is defined as a peak, whose signal-to-noise $(\mathrm{S} / \mathrm{N})$ ratio is $3: 1$. The limit of quantification (LOQ) is defined as a peak, whose signal-to-noise $(\mathrm{S} / \mathrm{N})$ ratio is $10: 1$. The results are listed in Table 1 .

2.5.3. System Suitability. System suitability was carried out to verify that resolution and reproducibility of the system were acceptable for the analysis. System suitability test was carried out by applying $6 \mu \mathrm{L}$ standard solutions of alpha-amyrin, beta-sitosterol, lupeol, and $n$-triacontane on TLC plate in six replicates under specified chromatographic conditions. The chromatograms were recorded. The values of percent relative standard deviations of peak area and retention factor of standards were taken as an indicator of system suitability. Since the values of percent relative standard deviations of peak area were found to be less than 2 and peaks were wellresolved, the method was suitable for analysis.

2.5.4. Specificity. The specificity of the proposed HPTLC method was ascertained by comparing visible chromatograms of alpha-amyrin, beta-sitosterol, lupeol, and ntriacontane standards with those found in the sample. The chromatograms were compared by overlay. Good correlation was observed between chromatograms obtained from alpha-amyrin, beta-sitosterol, lupeol, and $n$-triacontane standards and samples at all $R_{f}$ (alpha-amyrin- $R_{f} 0.68$, betasitosterol $-R_{f} 0.48$, lupeol $-R_{f} 0.61$, and $n$-triacontane $-R_{f}$ $0.91)$ values, respectively. 
TABLE 1: Method validation data for simultaneous quantification of alpha-amyrin, beta-sitosterol, lupeol, and $n$-triacontane from dried whole plant powder of Leptadenia reticulata (Retz.) Wight \& Arn. and Pluchea lanceolata (DC.) CB. Clarke.

\begin{tabular}{|c|c|c|c|c|}
\hline \multirow{2}{*}{ Parameters } & \multicolumn{4}{|c|}{ Results } \\
\hline & alpha-Amyrin & beta-Sitosterol & Lupeol & $n$-Triacontane \\
\hline Linear range ( $\mu \mathrm{g} /$ band $)$ & $0.1-1.0$ & $0.1-1.0$ & $0.1-1.0$ & $1.0-10.0$ \\
\hline Correlation coefficient $(r)$ & 0.999 & 0.999 & 0.999 & 0.999 \\
\hline LOD $(\mu \mathrm{g} / \mathrm{band})$ & 0.03 & 0.03 & 0.03 & 0.30 \\
\hline LOQ ( $\mu \mathrm{g} / \mathrm{band})$ & 0.10 & 0.10 & 0.10 & 1.00 \\
\hline Stability of standard solution & $\begin{array}{l}\text { Stable for minimum } \\
48 \text { hours }\end{array}$ & $\begin{array}{l}\text { Stable for minimum } \\
48 \text { hours }\end{array}$ & $\begin{array}{l}\text { Stable for minimum } \\
48 \text { hours }\end{array}$ & $\begin{array}{l}\text { Stable for minimum } \\
48 \text { hours }\end{array}$ \\
\hline $\begin{array}{l}\text { System suitability } \\
\text { (\% R.S.D.) }\end{array}$ & Less than 2 & Less than 2 & Less than 2 & Less than 2 \\
\hline \multicolumn{5}{|c|}{ Leptadenia reticulata (Retz.) Wight \& Arn. } \\
\hline $\begin{array}{l}\text { Repeatability-\% R.S.D. } \\
\text { range } \\
(n=3) \text { (on the same day) }\end{array}$ & $0.93 \pm 0.01$ & $0.99 \pm 0.06$ & $1.07 \pm 0.06$ & $1.23 \pm 0.06$ \\
\hline $\begin{array}{l}\text { Intermediate precision } \\
\% \text { R.S.D range }(n=9) \\
\text { (percent R.S.D. for three successive days) }\end{array}$ & $0.94 \pm 0.04$ & $0.99 \pm 0.06$ & $1.03 \pm 0.10$ & $0.93 \pm 0.04$ \\
\hline Assay $(\mathrm{mg} / 2 \mathrm{~g})$ & $0.99 \pm 0.01$ & $1.18 \pm 0.02$ & $0.62 \pm 0.06$ & $0.65 \pm 0.06$ \\
\hline Percent recovery & $99.01 \pm 0.07$ & $98.14 \pm 0.04$ & $98.60 \pm 0.01$ & $99.46 \pm 0.05$ \\
\hline \multicolumn{5}{|c|}{ Pluchea lanceolata (DC.) CB. Clarke. } \\
\hline $\begin{array}{l}\text { Repeatability-\% R.S.D. range } \\
(n=3) \text { (on the same day) }\end{array}$ & $1.00 \pm 0.05$ & $0.95 \pm 0.02$ & $1.00 \pm 0.03$ & N.D. \\
\hline $\begin{array}{l}\text { Intermediate precision } \\
\% \text { R.S.D range }(n=9) \\
\text { (percent R.S.D. for three successive days) }\end{array}$ & $0.96 \pm 0.05$ & $0.97 \pm 0.06$ & $0.98 \pm 0.05$ & N.D. \\
\hline Assay (mg/2 g) & $0.72 \pm 0.03$ & $1.61 \pm 0.06$ & $0.17 \pm 0.01$ & N.D. \\
\hline Percent recovery & $99.46 \pm 0.01$ & $99.25 \pm 0.02$ & $99.81 \pm 0.05$ & N.D. \\
\hline
\end{tabular}

${ }^{*}$ Note: N.D.: not detected.

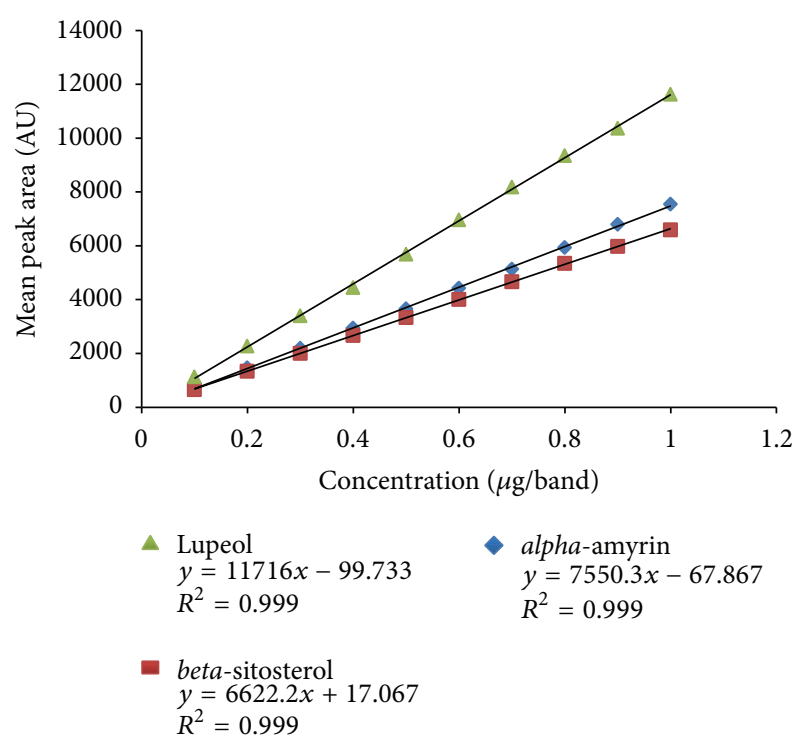

(a)

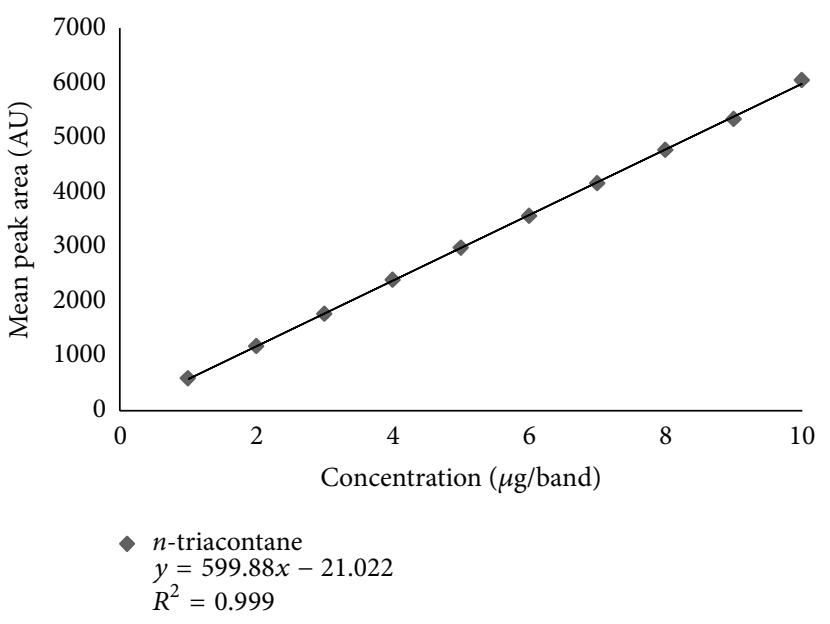

(b)

FIGURE 1: The figure represents a simultaneous plot of mean peak area v/s concentration of alpha-amyrin, beta-sitosterol, lupeol and $n$ triacontane standards, respectively. 
2.5.5. Precision. The method was validated in terms of repeatability and intermediate precision.

The repeatability was evaluated in triplicates by applying extract of both plant materials on TLC plate on the same day, under the specified chromatographic conditions. The peak areas of alpha-amyrin, beta-sitosterol, lupeol, and ntriacontane were recorded and assessed.

The intermediate precision of the method was evaluated by analyzing the sample solution in triplicate on three different days, under the specified chromatographic conditions. The peak areas of alpha-amyrin, beta-sitosterol, lupeol, and $n$-triacontane were recorded and assessed.

The precision results were expressed as percentage relative standard deviations of peak areas of alpha-amyrin, betasitosterol, lupeol, and $n$-triacontane. The results, listed in Table 1, indicate that the proposed method is precise and reproducible.

2.5.6. Standard Stability. The stabilities of standard alphaamyrin, beta-sitosterol, lupeol, and $n$-triacontane solution were determined by comparing the peak areas of the standard solution, and the stock solution was observed at different time intervals by spotting $6 \mu \mathrm{L}$ of working standard solution on TLC plate for a period of minimum $48 \mathrm{hrs}$ at room temperature. The results showed that the peak areas of alpha-amyrin, beta-sitosterol, lupeol, and $n$-triacontane almost remained unchanged (values of percent relative standard deviations were less than 2) over a period of $48 \mathrm{hrs}$, and no significant degradation was observed within the given period. Thus, the standard solutions of alpha-amyrin, beta-sitosterol, lupeol, and $n$-triacontane were stable for a minimum of $48 \mathrm{hrs}$.

2.5.7. Assay. The developed and validated HPTLC method was used for quantification of alpha-amyrin, beta-sitosterol, lupeol, and $n$-triacontane from the extract of dried whole plant powder of $L$. reticulata and P. lanceolata. $4.0 \mu \mathrm{L}$ of extract of both plant materials was applied as bands on the same TLC plate. The plate was developed and scanned under the specified chromatographic conditions. The chromatograms were recorded. To check the repeatability of the method, assay experiment was repeated seven times and the values of mean standard deviation (S.D.) and percent relative standard deviation (\%R.S.D.) were calculated. The results of assay experiment are shown in Table 1 . The amounts of alpha-amyrin, beta-sitosterol, lupeol, and $n$-triacontane present in each sample solution were determined from the calibration curve, by using the peak areas of alpha-amyrin, beta-sitosterol, lupeol, and $n$-triacontane in the sample.

2.5.8. Accuracy. The accuracy of the method was established by performing recovery experiment by using standard addition method at three different levels. To accurately weighed, about $1.0 \mathrm{~g}$ of dried whole plant powder of L. reticulata, known amounts of standards alpha-amyrin, beta-sitosterol, lupeol, and $n$-triacontane were added and extracted. Each of the three different levels containing sample solution and standard was applied in seven replicates on the same plate. The plate was then developed and scanned under the specified chromatographic conditions, as described earlier. The alphaamyrin, beta-sitosterol, lupeol, and $n$-triacontane contents were quantified by the proposed method and the percentage recovery was calculated. The same procedure was repeated for dried whole plant powder of $P$. lanceolata. except the addition of $n$-triacontane. The percent recovery values are shown in Table 1 .

\section{Results and Discussion}

During HPTLC analysis, several different mobile phases were tried for separation of alpha-amyrin, beta-sitosterol, lupeol, and $n$-triacontane from other phytochemicals present in whole plant powder of $L$. reticulata. Good separation was achieved with the mobile phase comprising pet-ether: ethyl acetate: acetonitrile in the volume ratio of $8: 2: 0.1$ along with prederivatization with iodine. Since, the phytochemicals, alpha-amyrin, beta-sitosterol, lupeol, and $n$-triacontane showed no UV and visible sensitivity on plate, the plate was postderivatized further with anisaldehyde-sulphuric acid reagent. The $R_{f}$ values for alpha-amyrin, beta-sitosterol, lupeol, and $n$-triacontane were $0.60,0.48,0.69$, and 0.91 , respectively. Figure 2 shows typical HPTLC chromatograms of standard alpha-amyrin, standard beta-sitosterol, standard lupeol, and standard $n$-triacontane in extracts of dried whole plant powder of $L$. reticulata and dried whole plant powder of P. lanceolata.

Literature survey revealed that some of the related methods were reviewed. A qualitative normal phase HPTLC method was reported [13] for separating and determining alpha-amyrin and lupeol from Brassica oleracea L. leaf extracts. HPTLC silica gel $60 \mathrm{~F}_{254}$ plates were used as stationary phase with the mobile phase as $n$-hexane-ethyl acetate in a volume ratio of $5: 1$. Postderivatization was carried out using anisaldehyde-sulphuric acid reagent. Identification of alphaamyrin and lupeol was carried out by visual comparison of the colour of alpha-amyrin and lupeol after derivatization. The reported method was unable to resolve the isomeric compounds alpha-amyrin and lupeol, because there was no significant difference in their $R_{f}$ values. In a reported method [9] chromatographic separation of twelve compounds including alpha-amyrin, lupeol, and beta-sitosterol from Brassica oleracea L., Solanum lycopersicum L., Rosmarinus officinalis L., Salvia officinalis L., and Quercus robur L. was studied. The study described a combination of two RP-HPTLC methods for a qualitative determination of twelve phytochemicals (alpha-amyrin, beta-amyrin, delta-amyrin, lupeol, lupenone, lupeol acetate, cycloartenol, cycloartenol acetate, ursolic acid, oleanolic acid, stigmasterol, and beta-sitosterol) and evaluation of their presence in different plant extracts. In the study, RP-HPTLC was used to analyse the phytochemicals. Experiment was performed on RP-HPTLC plates, using the combination of two mobile phases to isolate compounds; these were further identified using RP-HPLC method. The reported methods were only used for qualitative screening and identification of these compounds. Also capillary GC was used for quantitation of alpha-amyrin, beta-sitosterol, and lupeol from aerial part of J. anselliana. Solid phase extraction 


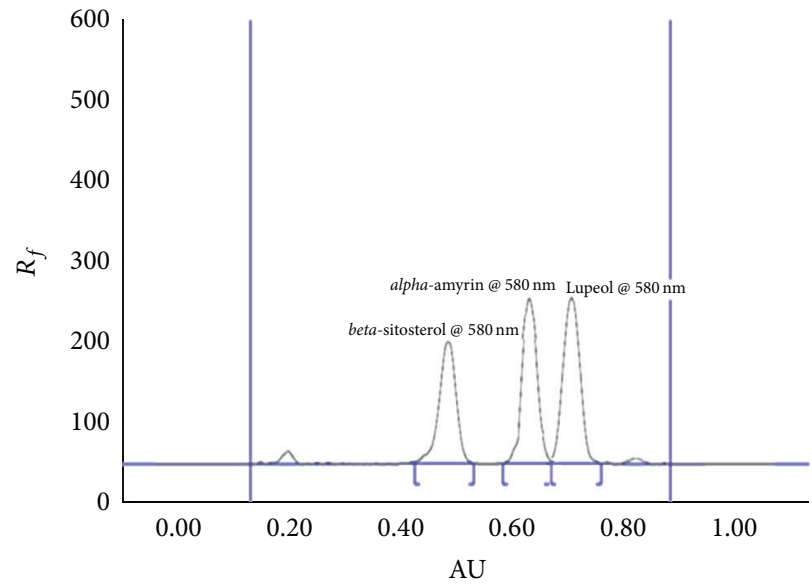

(a)

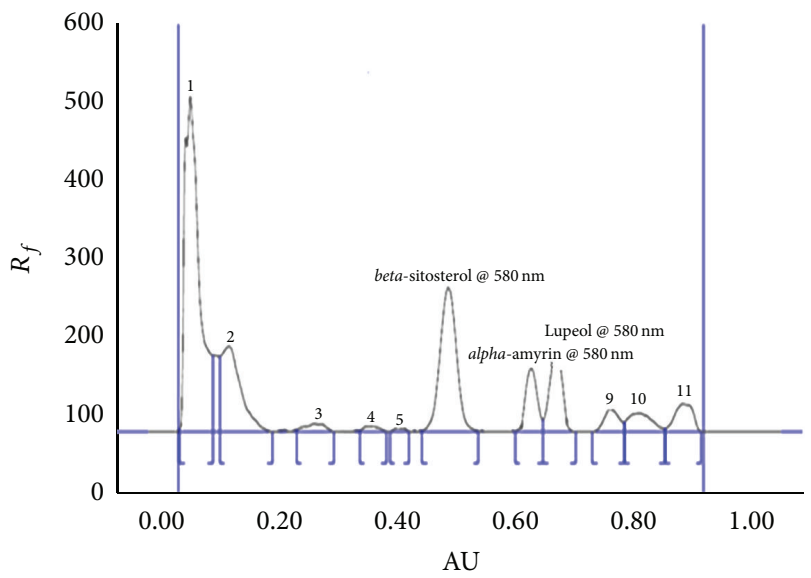

(c)

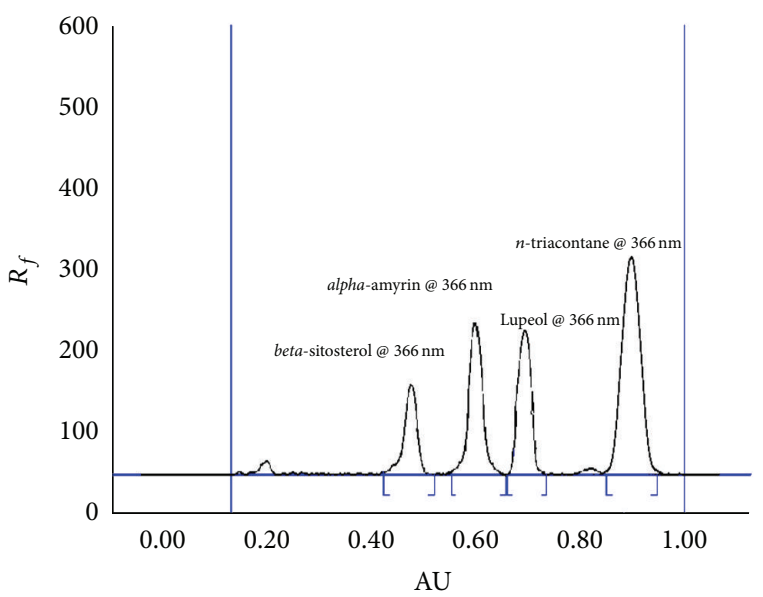

(b)

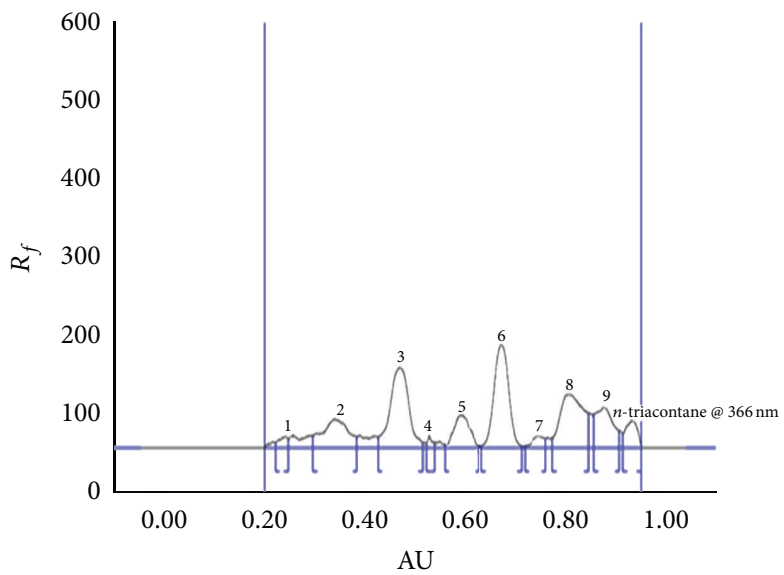

(d)

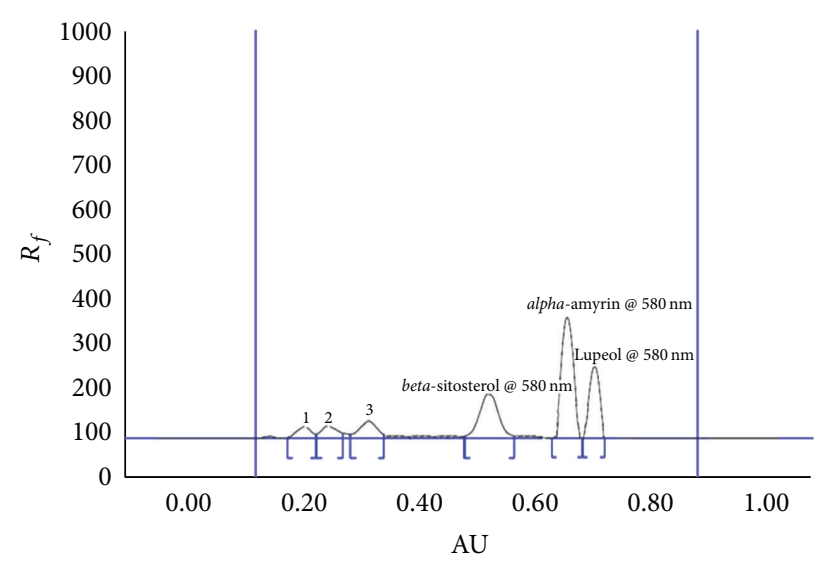

(e)

FiguRE 2: (a) and (b) represent HPTLC chromatogram of standard obtained at $\lambda=580 \mathrm{~nm}$ and $\lambda=366 \mathrm{~nm}$. (c) and (d) represent HPTLC chromatogram of sample L. reticulata obtained at $\lambda=580 \mathrm{~nm}$ and $\lambda=366 \mathrm{~nm}$. (e) represents HPTLC chromatogram of sample $P$. lanceoata obtained at $\lambda=580 \mathrm{~nm}$.

was used to remove the matrix [15]. A GC/MS method was reported for analysing compounds in Salvia bicolour Desf. extract. beta-Sitosterol and lupeol were detected. The retention time observed was $41.04 \mathrm{mins}$ for beta-sitosterol and 41.5 mins for lupeol [14]. Both methods were time consuming. Another method has been reported [16] to study the chemical constituents of the essential oil of Laggera pterodonta (DC.) Sch. Bip. using GC-MS. $n$-Triacontane was 
detected using Helium as carrier gas and injection done at elevated temperature of $250^{\circ} \mathrm{C}$. The flow rate of $1.61 \mathrm{~mL} / \mathrm{min}$ was used. Retention time observed for $n$-triacontane was 30.217. $n$-Triacontane was found to be $43.18 \%$ approximately. No HPTLC method has been reported for quantification of $n$-triacontane from whole plant powder of $L$. reticulata and $P$. lanceolata.

Therefore, in the present research work, in order to standardize the plants with these markers, a precise and accurate HPTLC method for simultaneous estimation of alpha-amyrin, beta-sitosterol, lupeol, and $n$-triacontane from the extract of whole plant powder of $L$. reticulata and $P$. lanceolata was developed. The present developed method is advantageous compared to the above reported methods as it uses a simple prederivatization technique of iodination which resolved the isomeric compounds, alpha-amyrin and lupeol. Also, alkanes are generally high molecular weight compounds and difficult to be analysed on TLC quantitatively. $n$ Triacontane which is an alkane has also been quantified. The mobile phase comprising petroleum ether: ethyl acetate: acetonitrile in the volume ratio of $8.2: 1.8: 0.1$ helped in resolving the phytoconstituents without the interference from sample matrix, with the development time of less than 10 minutes which helped in reduction of analysis time. Finally the developed plates were derivatized by anisaldehyde-sulphuric acid reagent. The developed method was validated following ICH guidelines criteria and is economical, simple, and rapid which can be easily performed at any laboratory conditions with specified parameters of HPTLC.

\section{Conclusion}

The developed HPTLC technique is simple, precise, specific, and accurate, which can be used for the routine quality control analysis and simultaneous quantitative determination of alpha-amyrin, beta-sitosterol, lupeol, and $n$-triacontane from the whole plant powder of L. reticulata and P. lanceolata. The method can be applied to effectively quantitate the presence of alpha-amyrin, beta-sitosterol, lupeol, and ntriacontane in other samples as well.

\section{Conflict of Interests}

The authors declare that there is no conflict of interests regarding the publication of this paper.

\section{Acknowledgments}

The authors wish to thank the Chemistry Department, Ruia College, India, for providing lab facility. The authors are also grateful to Anchrom HPTLC Technologists and special thanks go to their application specialist team, Mumbai. Also they are thankful to Dr. T. Prajapati, President of Cultivator Natural products, Dr. P. S. Nagar, MS University, and Dr. M. Parabia, (Dept. of Bioscience), Veer Narmad South Gujarat University.

\section{References}

[1] E. Reich and A. Schibli, High-Performance Thin-Layer Chromatography for the Analysis of Medicinal Plants, Thieme Medical, 2011.

[2] S. Srivastav, D. Deepak, and A. Khare, "Three novel pregnane glycosides from Leptadenia reticulata Wight and Arn," Tetrahedron, vol. 50, no. 3, pp. 789-798, 1994.

[3] V. N. Dwivedi, Bhav Prakash Nighantu, Hindi Translational Motilal Banarsidas Banaras, 1949.

[4] Anonymous, The Wealth of India Raw Materials Publication and Information Directorate, CSIR, New Delh, India, 1969.

[5] H. Wagner, Immunomodulatory Agents from Plants, pp. 291-292, Birkhäuser, Basel, Switzerland, 1st edition, 1998.

[6] B. S. Kaith, "Neolupeol and anti-inflammatory activity of Pluchea lanceolata," International Journal of Pharmacognosy, vol. 34, pp. 73-75, 1995.

[7] M. Ali, N. Ali Siddiqui, and R. Ramachandram, "Phytochemical investigation of aerial parts of Pluchea lanceolata C.B. Clarke," Indian Journal of Chemistry B, vol. 40, no. 8, pp. 698-706, 2001.

[8] L. Fraile, E. Crisci, L. Córdoba, M. A. Navarro, J. Osada, and M. Montoya, "Immunomodulatory properties of beta-sitosterol in pig immune responses," International Immunopharmacology, vol. 13, no. 3, pp. 316-321, 2012.

[9] M. Martelanc, I. Vovk, and B. Simonovska, "Separation and identification of some common isomeric plant triterpenoids by thin-layer chromatography and high-performance liquid chromatography," Journal of Chromatography A, vol. 1216, no. 38, pp. 6662-6670, 2009.

[10] "n-Triacontane," http://pubchem.ncbi.nlm.nih.gov/summary/ summary.cgi?cid=12535\#x299.

[11] C. P. Khare, Indian Herbal Remedies: Rational Western Therapy, Ayurvedic, and Other Traditional Usage and Botany, Springer, 2004.

[12] D. Mammen, M. Daniel, and R. T. Sane, "Seasonal and geographical variations in chemical constituents of Leptadenia reticulata," International Journal of Pharmaceutical Sciences Review and Research, vol. 4, no. 2, pp. 111-116, 2010.

[13] M. Martelanc, I. Vovk, and B. Simonovska, "Determination of three major triterpenoids in epicuticular wax of cabbage (Brassica oleracea L.) by high-performance liquid chromatography with UV and mass spectrometric detection," Journal of Chromatography A, vol. 1164, no. 1-2, pp. 145-152, 2007.

[14] T. A. Ibrahim, "Chemical composition and biological activity of extracts from Salvia bicolor desf. growing in Egypt," Molecules, vol. 17, no. 10, pp. 11315-11334, 2012.

[15] D. S. S. Kpoviéssi, F. Gbaguidi, J. Gbénou et al., "Validation of a method for the determination of sterols and triterpenes in the aerial part of Justicia anselliana (Nees) T. Anders by capillary gas chromatography," Journal of Pharmaceutical and Biomedical Analysis, vol. 48, no. 4, pp. 1127-1135, 2008.

[16] E. H. Omoregie, K. F. Oluyemisi, O. S. Koma, and O. J. Ibumeh, "Chemical constituents of the essential oil of laggera pterodonta (DC.) sch. bip. from north-central Nigeria," Journal of Applied Pharmaceutical Science, vol. 2, no. 8, pp. 198-202, 2012. 

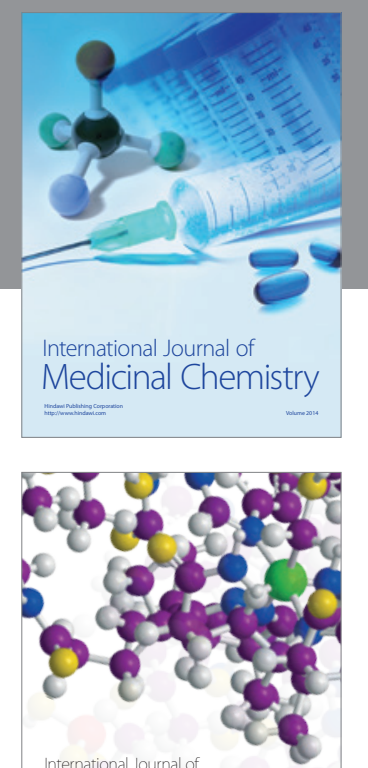

\section{Carbohydrate} Chemistry

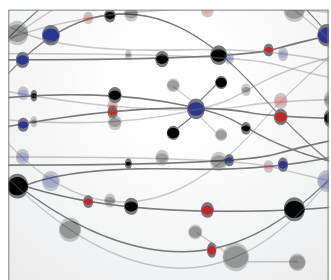

The Scientific World Journal
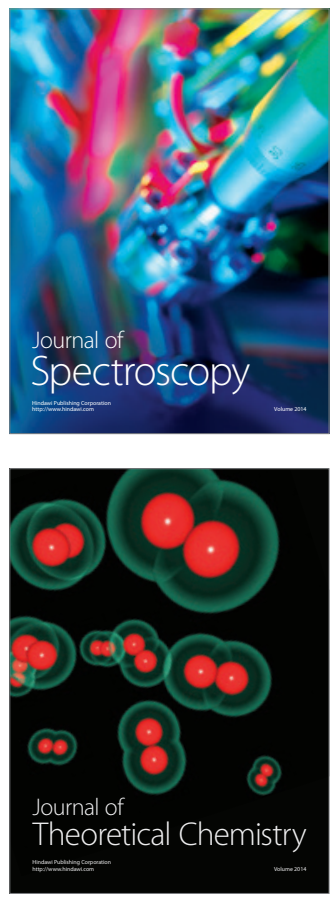
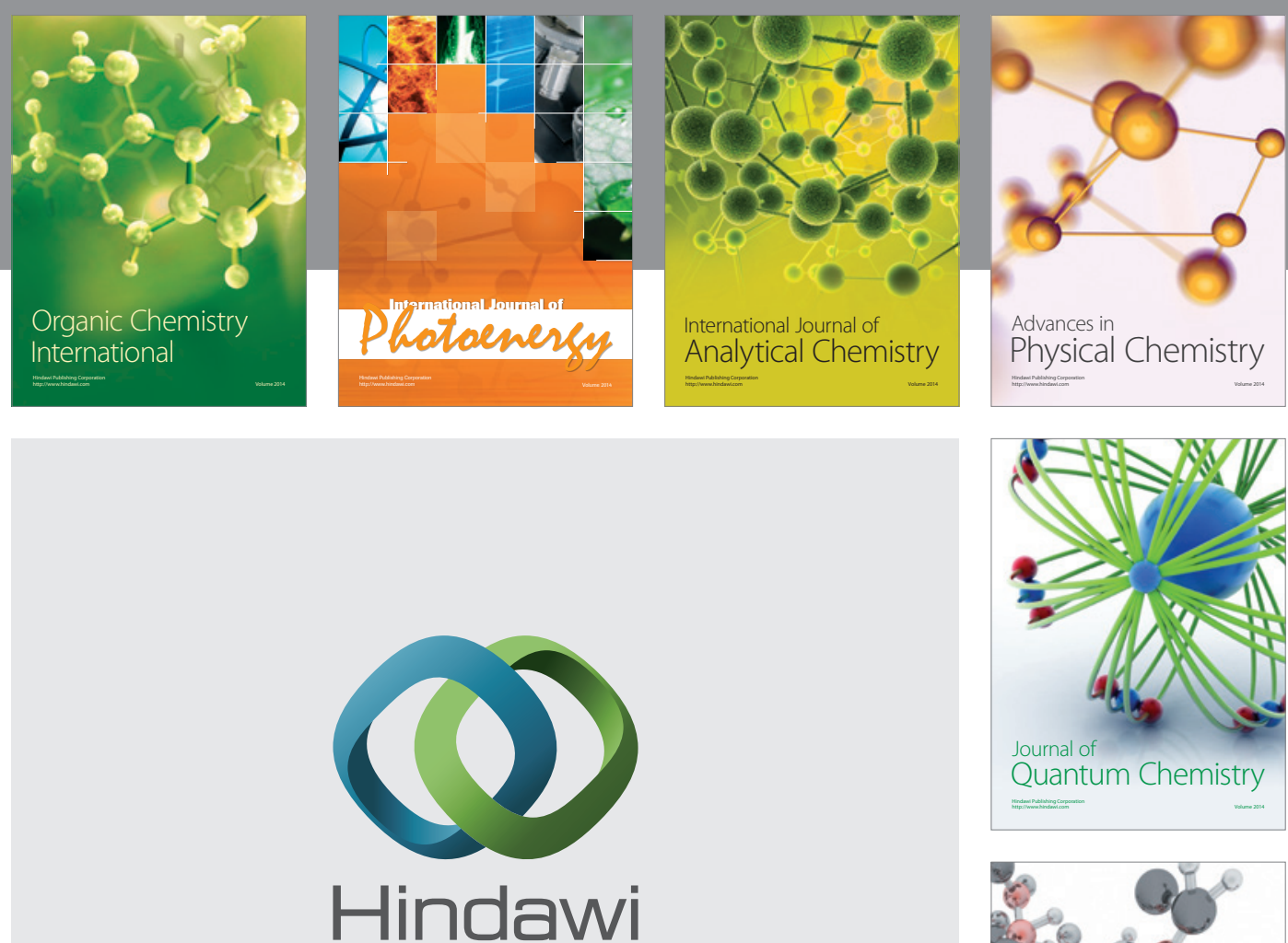

Submit your manuscripts at

http://www.hindawi.com

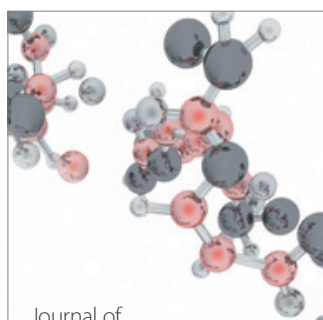

Analytical Methods

in Chemistry

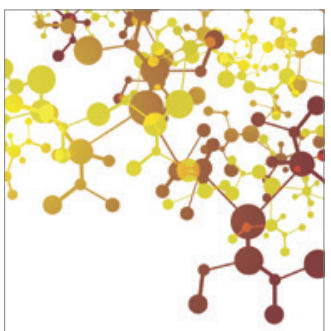

Journal of

Applied Chemistry

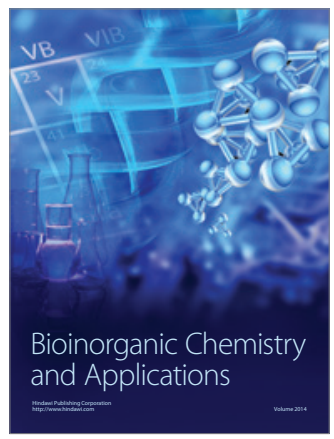

Inorganic Chemistry
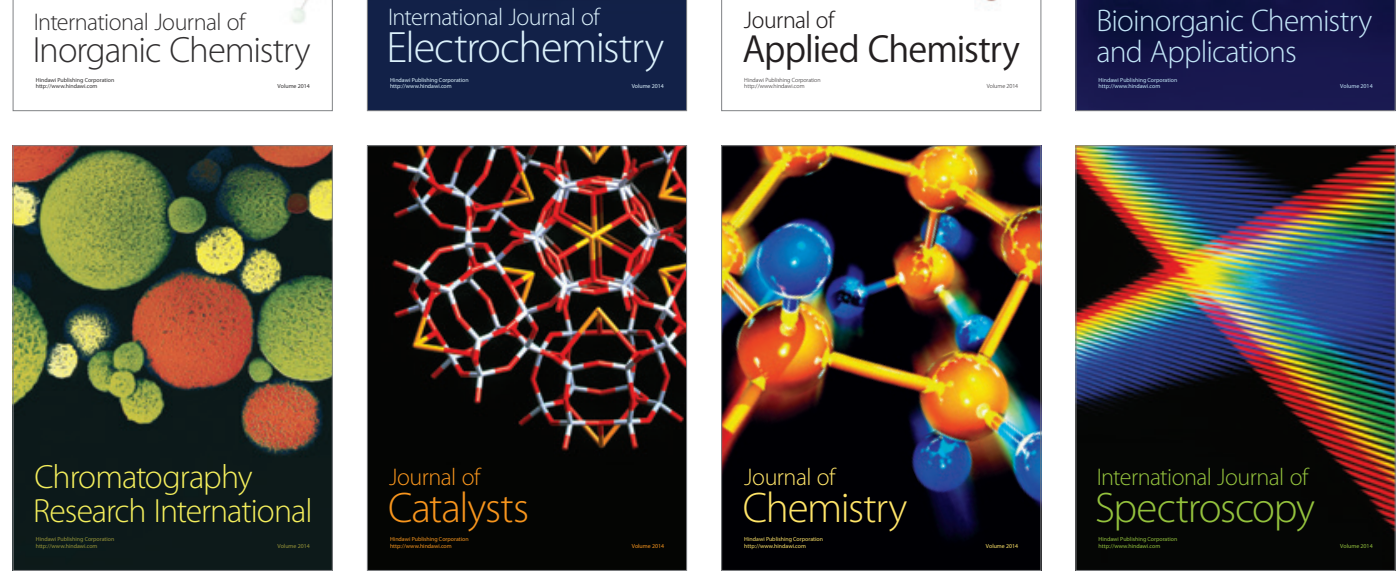